\title{
Solução de aterro sanitário rentável para a cidade de Araçatuba, SP
}

\author{
Cost-effective landfill solution for Araçatuba city, SP \\ Solución de relleno sanitario rentable para la ciudad de \\ Araçatuba, SP
}

\begin{abstract}
Ricardo Henrique Maschio Vieira ${ }^{1}$
William Seiji Inagaki Suda² Vicente Luiz Rodrigues Tavares ${ }^{3}$ Camila Fernanda Marsal Breda ${ }^{4}$ Luis Filipi Bianco Gavioli ${ }^{5}$ Natalia Felix Negreiros ${ }^{6}$
\end{abstract}

${ }^{1}$ Graduando de Engenharia Civil no Centro Universitário Católico Salesiano Auxilium, Araçatuba, SP. E-mail: rico_hmv@hotmail.com

${ }^{2}$ Graduando em Engenharia Civil, Graduado em Engenharia da Computação e Especialista em Redes, Conceitos, Estruturas e Segurança pelo Centro Universitário Católico Salesiano Auxilium, Araçatuba, SP. E-mail:william_suda@yahoo.com.br

${ }^{3}$ Graduando em Engenharia Civil pelo Centro Universitário Católico Salesiano Auxilium, Araçatuba, SP. E-mail: vicent.r.tavares@gmail.com

${ }^{4}$ Graduanda em Engenharia Civil pelo Centro Universitário Católico Salesiano Auxilium, Araçatuba, SP. E-mail: camilla_breda@hotmail.com

${ }^{5}$ Graduando em Engenharia Civil pelo Centro Universitário Católico Salesiano Auxilium, Araçatuba, SP. E-mail: luis.bgi@hotmail.com

${ }^{6}$ Mestre e Doutora em Ecologia e Recursos Naturais pela Universidade Federal de São Carlos (UFSCAR). Graduada em Ciências Biológicas pela Universidade Federal de Alfenas (UNIFAL), MG. Docente no Centro Universitário Católico Salesiano Auxilium, Araçatuba, SP. E-mail: natalia_felix@yahoo.com.br 
Resumo: O presente trabalho tem como finalidade principal solucionar o problema de descarte de materiais sólidos em aterro sanitário, que se agrava a cada dia na cidade de Araçatuba-SP, e o intuito adjacente de fazer com que o local aumente a sua capacidade de acolhimento que se encontra no limite e assim realizar o reaproveitamento do lixo recebido em húmus. Devido ao problema de proximidade do aterro ao aeroporto da cidade, o município acabou não dando continuidade a obras futuras, mesmo tendo adquirido um terreno próximo para possíveis ampliações, o qual está incluso neste projeto, de modo a dar continuidade a trabalhos antigos. A falta de planejamento e estudo da sustentabilidade envolvida no entorno do terreno levou à paralização dessas obras, que podem trazer para a região, além de tempo de sobra para acomodação dos resíduos, a alternativa de se realizar um trabalho paralelo e rentável na área da produção de adubo orgânico, podendo servir de exemplo a muitas outras áreas com as mesmas restrições e que estão em limite de vida útil.

Palavras-chave: saneamento; sustentabilidade; resíduos sólidos.

\begin{abstract}
The main objective of this work is to solve the problem of disposal of solid materials in landfills, which is worsening every day in the city of Araçatuba, SP, and the adjacent intention to do with the site increases its capacity of reception that is in the limit and as well as to carry out the reuse of rubbish received in humus, due to the problem with the proximity of the landfill of the city or municipal airport, it ended up not giving continuity as future works, even having acquired a land nearby for extensive extensions, project, to give continuity old work and due to the lack of planning and study of sustainability involved in the environment of the terrain and that ended up paralyzed, brings to a region beyond the time to spare for waste the alternative to perform a parallel work and rent in the area of production of organic fertilizer and can serve as an example to many others with as equal $\mathrm{S}$ restrictions and that are in I Life.
\end{abstract}

Keywords: sanitation; sustainability; solid waste.

Resumen: Este trabajo tiene como objetivo principal resolver el problema de la eliminación de materiales sólidos en el relleno sanitario, lo que empeora cada día en la ciudad de Araçatuba-SP, y el orden adyacente a hacer que el sitio para aumentar su capacidad de carga que en el límite y así lograr la reutilización de los residuos recibidos en humus, debido al problema con la proximidad del lugar al aeropuerto de la ciudad de la ciudad terminó por no continuar los trabajos futuros, incluso después de haber adquirido un suelo cerca de posibles expansiones, que se incluye este proyecto para continuar las obras antiguas y debido a la falta de planificación y estudio de la sostenibilidad involucrado en el medio terrestre y que todo ha terminado para paralizada, trae a la región, así como un montón de tiempo para adaptarse a la alternativa de realizar los residuos y un trabajo rentable paralelo en el área de la producción de compost ejemplo puede servir muchos otros con el mismo s restricciones y están en límite de por vida.

Palabras clave: saneamento; sostenibilidad; residuos sólidos. 


\section{INTRODUÇÃO}

A cidade de Araçatuba está localizada na região noroeste do estado de São Paulo, é um município sede, e sua Região Administrativa (RA) é composta por 43 municípios distribuídos em duas regiões de governo (Araçatuba e Andradina), que ocupam $23.952 \mathrm{~km}^{2}$ do território paulista, o que representa $7,5 \%$ do total do Estado. Está localizada na região noroeste de São Paulo,

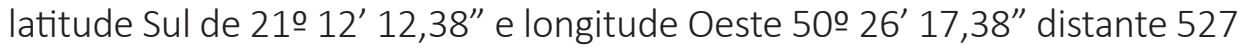
quilômetros por rodovia da capital. Existem 43 escolas no município, 1211 docentes para o ensino fundamental, 522 docentes para o ensino médio (IBGE, 2009), possuindo oito faculdades: duas públicas e seis particulares $(G 1,2014)$.

De acordo com o Instituto Brasileiro de Geografia e Estatística (ARAÇATUBA, s.d.), a topografia da área urbana é plana, de relevo suave e extensas chapadas. A Praça Rui Barbosa é o epicentro da cidade com altitude de 402,91m em relação ao nível do mar. O solo é caracterizado por ser sílico argiloso, com depósitos de húmus nas baixas de terreno, arenitos e siltitos nas partes carbonáticas, conglomerados e folhelhos.

O município de Araçatuba, SP, possui temperatura média entre 19ㄷ a 28으 e estação seca ao longo do inverno (SILVA, 2014).

Em relação às bacias hidrográficas, a bacia onde Araçatuba se localiza é a bacia Córrego Baguaçu, que possui aproximadamente $614 \mathrm{~km}^{2}$ de área e extensão de 55 km, situada no Planalto Ocidental Paulista, uma região que oferece graves problemas relacionados à erosão naturalmente e apresenta também erosão acelerada, decorrente das intervenções humanas ao longo do tempo. O Córrego Baguaçu corresponde a cerca de 70\% do abastecimento de águas em Araçatuba (SILVA, 2014).

Conforme o plano Municipal de Abastecimento de Água e Esgotamento Sanitário do Município de Araçatuba, a ocupação da área se apresenta da seguinte maneira: área de uso misto com predominância de atividades comerciais e de serviços na área central e avenidas principais, residências no restante da área e existência de lotes não ocupados ao longo das avenidas marginais. Sua economia é historicamente ligada à pecuária, sendo conhecida como cidade do boi gordo e, posteriormente, cidade do asfalto. O setor sucroalcooleiro está em crescimento acelerado e precisa de novas áreas para se expandir. 
O município de Araçatuba possui um considerável potencial em desenvolvimento nas áreas de transportes, economia e em mão de obra qualificada e, com isso, o setor terciário vem crescendo e tomando grandes proporções, o que é benéfico para região que é um dos principais centros agropecuários e de apoio a serviços de comércio do país.

Os produtos que mais têm destaque no mercado exterior são a cana de açúcar, os alimentos lácteos, carne bovina e os fios cirúrgicos, no qual a atividade industrial conta com a presença de mais de 100 indústrias que movimentam as exportações a níveis de $38 \%$ a mais conforme a Secretaria de Comércio Exterior (SECEX).

A cidade Araçatuba possui $100 \%$ de coleta e tratamento de esgoto, sendo $70 \%$ através de lodo ativo e $30 \%$ pelas lagoas de estabilização, possui duas estações que abrangem as quatro bacias: Tropeiros, Espanhóis, Machado de Mello e Baguaçu, sub-bacia Água Branca. A ETE-SANEAR está em funcionamento desde 2000 e recebe o esgoto das bacias Machado de Melo e Baguaçu, através de duas estações de bombeamento, que estão localizadas em cada uma dessas bacias contribuintes. A moderna estação é administrada pela Soluções Ambientais de Araçatuba (SAMAR) desde 2015. O processo de tratamento adotado é o biológico, reduzindo a carga orgânica do esgoto em mais de 95\%, garantindo a recuperação dos cursos d'água da cidade (SAMAR, 2016).

São necessárias coletas diárias para monitoramento da rede de distribuição de água, para que exista um acompanhamento rigoroso do controle de qualidade, efetuando assim análises físico-químicas e bacteriológicas da água disponibilizadas para a população. Os pontos de coletas são cotados em 473 lugares espalhados pelo município, totalizando 1000 análises no mês seguindo o padrão implantado pela Organização Mundial de Saúde (OMS), realizando coletas de água tratada em todas as etapas do processo de tratamento para que se tenha eficiência no produto final entregue à população.

A área prevista para a ampliação do aterro sanitário municipal está localizada ao lado do atual, na Estrada do Artista, 450, Latitude $21^{\circ} 11^{\prime}$ 36.44" S, Longitude 50²3' 41.41" O.

Essa área foi desapropriada no ano de 1999, com a finalidade de ampliação do atual aterro, porém, no ano de 2010, o governo municipal 
da época retirou a proposta de licenciamento ambiental, e, no dia 16 de outubro de 2012, começou a vigorar a Lei Federal n. 12.725/2012, que impede a instalação de aterros sanitários ou outras atividades que possam comprometer a segurança do espaço aéreo em um raio de $20 \mathrm{~km}$ de aeroportos, pela possibilidade de haver aves nesse espaço. A área está com uma distância de aproximadamente 6,50 km do Aeroporto Dario Guarita. Serão apresentadas as justificativas demonstrando os motivos pelos quais hoje essa é a melhor área para a destinação dos resíduos sólidos gerados pela população de Araçatuba (GALDINO, 2016).

Foi retirado o licenciamento ambiental no ano de 2010 para ampliação do atual aterro, e emitida a certidão para uma empresa privada no ano de 2011. A área adquirida está localizada no bairro da Pratinha, município de Araçatuba, SP, Rodovia Zequinha de Abreu, Latitude 210 18' 28.17" S, Longitude 50 32' 38.90".

O aterro sanitário na área do bairro da Pratinha não atende a diversas leis e normas ambientais, o risco de contaminação do ar, solo, águas superficiais e subterrâneas é alto, aumentaria o trânsito de caminhões no local, onde a via não atende as necessidades, há possibilidade de desvalorização dos imóveis urbanos e rurais aos arredores do aterro instalado, além de a distância mínima do aterro sanitário em relação a residências isoladas não atender a distância mínima de 500 metros exigida pela Secretaria do Meio Ambiente do Estado de São Paulo (MANSOR et al., 2010), pois existem residências em um raio menor de 100 metros. A região dentro do plano diretor pertence ao Z 5 (Zona de Produção Agrícola Sustentável), contendo quatro bairros rurais (Pratinha, Prata, Água Limpa e Jacutinga), ricos na produção de alimentos como leite, banana, mandioca e hortaliças.

O atual aterro sanitário de Araçatuba recebeu nota 9,6 pela Companhia Ambiental do Estado de São Paulo (CETESB) (2014), realizando a gestão de resíduos sólidos de maneira correta, não havendo a necessidade de um aterro sanitário regional para o recebimento inicial dos resíduos de $31 \mathrm{mu}$ nicípios. Porém a região está localizada em uma área com nascentes dos córregos da Água Limpa (afluente do Baguaçu, que abastece Araçatuba), e o córrego da Prata (afluente do Córrego Azul). Além de todos os problemas ambientais citados anteriormente, a área no bairro da Pratinha possui uma 
das residências com a distância de somente 60 metros, sendo que, de acordo com a Secretaria de Meio Ambiente do Estado de São Paulo (SILVA, 2010), deve haver distância mínima de 500 metros de residências isoladas. A existência de duas nascentes dentro da área e uma nascente próxima contraria também a norma da Associação Brasileira de Normas Técnicas (ABNT) NBR 13.896/1997, segundo a qual a distância mínima entre um aterro e corpos d'água deve ser de 200 metros (FURTADO, 2015).

Durante os trabalhos do Comitê da Bacia Hidrográfica do Baixo Tietê, esse assunto foi discutido e, com base em parecer técnico elaborado pela Associação dos Engenheiros e Arquitetos da Alta Noroeste (AEAN), de autoria da Enga. Me. Zeide Nogueira de C. Furtado (FURTADO, 2013), entre outros, foram informadas as razões técnicas pela desaprovação de empreendimentos dessa natureza naquele local, com o registro da ART 92221220130564039 CREA SP. Disso resultou a Deliberação do Comitê da Bacia Hidrográfica do Baixo Tietê (CBH-BT n. 124/2013), que diz em seu Artigo Primeiro: "não é do interesse do Comitê da Bacia Hidrográfica do Baixo Tietê que empreendimentos desta natureza sejam implantados em locais onde haverá interferências e impactos nos recursos hídricos". Existe a preocupação em relação à instalação desse aterro, pois está localizado a montante do Córrego Azul, sendo esse o manancial de abastecimento da área rural, e também da área urbana do município de Guararapes.

Em Araçatuba, existe uma lei municipal n. 6.904, de 04 de setembro de 2007, que proíbe o recebimento de lixo de qualquer natureza proveniente de outros municípios no aterro sanitário de Araçatuba. No dia 11 de março de 2013, houve uma nova proposta contra o recebimento de lixo de outros municípios no aterro sanitário ou em qualquer outro equipamento ou empreendimento público, privado ou público-privado no município de Araçatuba, então novamente aprovada em plenário, porém não houve o veto e também não foi sancionada pelo prefeito, sendo assim foi promulgada, no dia 12 de abril de 2013, como Lei Municipal n. 7.525, de 12 de abril de 2013. No início do ano de 2016, foi realizada uma nova tentativa para a instalação do aterro sanitário por meio político, através de uma proposta do poder executivo de uma Parceria Público Privada (PPP) no dia 6 de janeiro de 2016, porém rejeitada pela maioria do legislativo. No dia 7 de março 
de 2016, a Justiça de Araçatuba concedeu uma liminar com o qual proíbe a implantação do aterro sanitário no bairro da zona rural da Pratinha, e a certidão concedida pela Prefeitura Municipal de Araçatuba está suspensa até o julgamento final do processo. Essa decisão da Justiça foi feita através de Medida Cautelar de Produção Antecipada de Prova, imposta pelo Ministério Público Estadual- Promotoria de Justiça de Habitação e Urbanismo e Meio Ambiente de Araçatuba, cujo embasamento técnico tem como origem a vistoria na área do aterro e parecer técnico de profissional compromissado, regular e devidamente habilitado, com ART 92221220150785992 CREA SP, recolhida (FURTADO, 2015).

O problema central da ampliação da área do aterro é a distância mínima de $20 \mathrm{Km}$ de raio do aeroporto municipal; porém, no município de Paulínia, a distância entre o aterro sanitário e o aeroporto de Americana é inferior a 20 quilômetros, distando apenas 6,50 quilômetros, e, no dia 13 de março de 2014, a CETESB concedeu a ampliação desse aterro.

O aterro de Paulínia pertence à empresa "Estre Ambiental", e recebe não somente os resíduos de Paulínia, como também da Região Metropolitana de Campinas, e de outras regiões. Hoje recebe resíduos de 35 municípios, sendo que somente 14 são da região metropolitana de Campinas. Os resíduos são domiciliares e industriais de classe IIA (Não Inertes: resíduos com propriedades de biodegradabilidade, combustibilidade ou solubilidade em água) e IIB (Inertes: resíduos que, quando submetidos a um contato com água, não terão nenhum de seus constituintes solubilizados a concentrações superiores aos padrões de potabilidade da água, como por exemplo, rochas, tijolos, vidros, certos plásticos e borrachas). Essas classificações estão de acordo com a norma da ABNT NBR 10.004/2004. São recebidas diariamente 5.000 toneladas de resíduos, desde o ano 2000, quando foram iniciadas suas atividades no município.

A ampliação do aterro de Paulínia sanitário foi concedida pela CETESB no Parecer Técnico n. 022/14/IPSR, considerando a convivência e viabilidade de ampliação do Aterro em área próxima ao CGR Paulínia, tendo em vista o aproveitamento da infraestrutura e da logística implantada no atual empreendimento, além da continuidade das operações de outras unidades de apoio existentes no local. 
Foi realizada análise inicial do Plano Diretor do Município de Paulínia (Lei n. 2.852/2006), da Lei de Uso e Ocupação do Solo (Lei Complementar n. 53/2011), do Mapa de Zoneamento e da Lei Orgânica do município de Paulínia com o objetivo de identificar as potenciais áreas de implantação, de acordo com a compatibilidade entre as diretrizes de uso e a tipologia do empreendimento proposto, apontando quatro áreas potenciais sem restrições legais. No município de Araçatuba, de acordo com o Plano Diretor do Município, a área adquirida por eles está dentro da Z 5 (Zona de Produção Agrícola Sustentável) e não na Z 4 (Zona de Desenvolvimento Regional) que seria a zona correta.

A área onde foi autorizada a ampliação em Paulínia possui 40 hectares, ou seja, $400.000 \mathrm{~m}^{2}$, e o terreno onde desejamos realizar a ampliação possui $70.000 \mathrm{~m}^{2}$. Esse aterro foi licenciado para o recebimento diário de 5.000 toneladas por dia, Araçatuba gera por dia cerca de 169,17 toneladas de resíduos. Interferência em Segurança Aeroportuária, a esse item faz referência a Resolução do CONAMA n. 4 (1995), que estabelece as Áreas de Segurança Aeroportuária (ASAs) e a necessidade de proteção de áreas no entorno do aeródromo, ou seja, prevenir a implantação de atividades de natureza perigosa que possam estar servindo como foco para atração de aves.

A Lei Federal n. 12.725/2012 discorre sobre o controle da fauna nas imediações de aeródromos, a ASA nessa lei é definida como uma área circular do território de um ou mais municípios, definida a partir do centro geométrico da maior pista do aeródromo ou aeródromo militar, em um raio de 20 km, sendo que, nesse espaço, o uso e ocupação estão sujeitos a restrições em função da natureza atrativa da fauna.

No Plano Básico de Gerenciamento do Risco Aviário (PBGRA), aprovado pela portaria n. 249/GC5 no dia 06 de maio de 2011, do comando da Aeronáutica do Ministério da Defesa, a Área de Gerenciamento de Risco Aviário (AGRA) é uma área circular com centro no ponto médio da pista do aeródromo e raio de 20 quilômetros; a AGRA possui um setor interno, também chamado de núcleo, com raio de 9 quilômetros, e um setor externo, compreendido entre o núcleo e o seu limite. Apontados esses itens dentro do Parecer Técnico n. 022/14/IPSR da CETESB, o pare- 
cer técnico n. 2/40/2014, emitido em 23 de janeiro de 2014, pelo Quarto Serviço Regional de Investigação e Prevenção de Acidentes Aeronáuticos do Comando da Aeronáutica do Ministério da Defesa, foi relatado o seguinte pronunciamento:

[...] o empreendimento será adequado em uma área [...] contígua ao que está em operação [...] distante 6.550 metros do Aeródromo Municipal de AMERICANA (SDAI). Considerando a visita técnica do SERIPA IV no empreendimento em 19/12/2013, na qual foi constatada que a empresa emprega técnicas mitigadoras e de exclusão de aves, operando de acordo com as regras aplicáveis [...]. Desta forma, considerando o exposto acima, informo a V. Exa. que este Serviço Regional não se opõe à adequação do Aterro Sanitário denominado Centro de Gerenciamento de Resíduos proposto pela empresa ESTRE AMBIENTAL, no município de Paulínia (SP), desde que sejam mantidos procedimentos operacionais que caracterizam o local como aterro sanitário, de acordo com as normas vigentes. (BRASIL, 2011).

A única recomendação por parte da CETESB foi a manifestação favorável do órgão da Aviação Civil, e apresentação pelo empreendedor de um Programa de Monitoramento e Controle de Avifauna detalhado, visando à segurança aeroportuária, a ser implementado durante o período que o aterro sanitário estiver funcionando.

De acordo com o Inventário Estadual de Resíduos Sólidos Urbanos (CETESB, 2014), os resultados do IQR (Índice de Qualidade de Resíduos) obtidos por Araçatuba e Paulínia, no ano de 2014, foram Araçatuba com 9,6 e Paulínia obteve 9,8.

Com a atualização da PBGRA, em 2017, o aterro passou a ser aceitável devido a distância, que passou a ser de no mínimo 5 km (BRASIL, 2017).

Assim, o presente estudo baseia-se no aterro de Paulínia, SP, que também possui o histórico de distância inferior e está em operação legal atualmente. Com a iniciativa de melhora e aumento das condições do aterro sanitário já existente e em funcionamento na cidade de Araçatuba, SP, este, além de receber resíduos com segurança por mais tempo, em vista que está com prazo de validade próximo, poderá gerar rentabilidade e mais empregos com a coleta de chorume, produção e comercialização de adubo solúvel em água e a prática de minhocultura. 


\section{MATERIAL E MÉTODOS}

O estudo qualitativo foi baseado na pesquisa de artigos científicos em bases de dados online LILACS, SciELO e consulta a livros. Foi realizada uma busca sobre operação de Aterros Sanitários, considerando os títulos e os resumos dos artigos para a seleção ampla de prováveis trabalhos de interesse.

\section{RESULTADOS E DISCUSSÃO}

O aterro projetado apresenta uma vida útil de 20 anos, de forma a atender a expectativa futura com base nos anos de 2016 a 2035; a projeção foi realizada a partir do método logístico, apresentado na Tabela 1.

Tabela 1 - Projeção da população urbana no município de Araçatuba, SP, nos anos de operação do Aterro Sanitário, a partir do método logístico

\begin{tabular}{ll|ll|ll|ll}
\hline \multicolumn{6}{c}{ População urbana correspondente aos anos de alcance (habitantes) } \\
\hline $\mathbf{2 0 1 6}$ & 189.682 & $\mathbf{2 0 2 1}$ & 198.419 & $\mathbf{2 0 2 6}$ & 208.575 & $\mathbf{2 0 3 1}$ & 220.506 \\
\hline $\mathbf{2 0 1 7}$ & 191.330 & $\mathbf{2 0 2 2}$ & 200.327 & $\mathbf{2 0 2 7}$ & 210.806 & $\mathbf{2 0 3 2}$ & 223.145 \\
\hline $\mathbf{2 0 1 8}$ & 193.025 & $\mathbf{2 0 2 3}$ & 202.294 & $\mathbf{2 0 2 8}$ & 213.111 & $\mathbf{2 0 3 3}$ & 225.878 \\
\hline $\mathbf{2 0 1 9}$ & 194.771 & $\mathbf{2 0 2 4}$ & 204.322 & $\mathbf{2 0 2 9}$ & 215.493 & $\mathbf{2 0 3 4}$ & 228.711 \\
\hline $\mathbf{2 0 2 0}$ & 196.568 & $\mathbf{2 0 2 5}$ & 206.415 & $\mathbf{2 0 3 0}$ & 217.957 & $\mathbf{2 0 3 5}$ & 231.649 \\
\hline
\end{tabular}

A geração per capita de resíduos é de aproximadamente $0,74 \mathrm{~kg} /$ habitantes*dia conforme IBGE (2002). Dessa forma, foi adotada uma coleta geral de todo lixo do município (Tabela 2).

Tabela 2 - Projeção da quantidade de resíduos gerados e coletados, a partir da população urbana no município de Araçatuba, SP, nos anos de operação do Aterro Sanitário

\begin{tabular}{ll|lll|ll|ll}
\hline \multicolumn{8}{c}{ Quantidade de resíduo gerado e coletado (kg/dia) } \\
\hline $\mathbf{2 0 1 6}$ & $140.364,68$ & $\mathbf{2 0 2 1}$ & $146.830,06$ & $\mathbf{2 0 2 6}$ & $154.345,50$ & $\mathbf{2 0 3 1}$ & $163.174,44$ \\
\hline $\mathbf{2 0 1 7}$ & $141.584,20$ & $\mathbf{2 0 2 2}$ & $148.241,98$ & $\mathbf{2 0 2 7}$ & $155.996,44$ & $\mathbf{2 0 3 2}$ & $165.127,30$ \\
\hline $\mathbf{2 0 1 8}$ & $142.838,50$ & $\mathbf{2 0 2 3}$ & $149.697,56$ & $\mathbf{2 0 2 8}$ & $157.702,14$ & $\mathbf{2 0 3 3}$ & $167.149,72$ \\
\hline $\mathbf{2 0 1 9}$ & $144.130,54$ & $\mathbf{2 0 2 4}$ & $151.198,28$ & $\mathbf{2 0 2 9}$ & $159.464,82$ & $\mathbf{2 0 3 4}$ & $169.246,14$ \\
\hline $\mathbf{2 0 2 0}$ & $145.460,32$ & $\mathbf{2 0 2 5}$ & $152.747,10$ & $\mathbf{2 0 3 0}$ & $161.288,18$ & $\mathbf{2 0 3 5}$ & $171.420,26$ \\
\hline
\end{tabular}


A quantidade anual de resíduo gerado e coletado está expressada na Tabela 3.

Tabela 3 - Projeção da quantidade anual de resíduos gerados e coletados (Toneladas/ano) a partir da população urbana no município de Araçatuba, $\mathrm{SP}$, nos anos de operação do Aterro Sanitário

\begin{tabular}{ll|ll|ll|ll}
\hline \multicolumn{6}{c}{ Quantidade anual de resíduo gerado e coletado (toneladas/ano) } \\
\hline $\mathbf{2 0 1 6}$ & $51.233,11$ & $\mathbf{2 0 2 1}$ & $53.592,97$ & $\mathbf{2 0 2 6}$ & $56.336,11$ & $\mathbf{2 0 3 1}$ & $59.558,67$ \\
\hline $\mathbf{2 0 1 7}$ & $51.678,23$ & $\mathbf{2 0 2 2}$ & $54.108,32$ & $\mathbf{2 0 2 7}$ & $56.938,70$ & $\mathbf{2 0 3 2}$ & $60.271,46$ \\
\hline $\mathbf{2 0 1 8}$ & $52.136,05$ & $\mathbf{2 0 2 3}$ & $54.639,61$ & $\mathbf{2 0 2 8}$ & $57.561,28$ & $\mathbf{2 0 3 3}$ & $61.009,65$ \\
\hline $\mathbf{2 0 1 9}$ & $52.607,65$ & $\mathbf{2 0 2 4}$ & $55.187,37$ & $\mathbf{2 0 2 9}$ & $58.204,66$ & $\mathbf{2 0 3 4}$ & $61.774,84$ \\
\hline $\mathbf{2 0 2 0}$ & $53.093,02$ & $\mathbf{2 0 2 5}$ & $55.752,69$ & $\mathbf{2 0 3 0}$ & $58.870,19$ & $\mathbf{2 0 3 5}$ & $62.568,39$ \\
\hline
\end{tabular}

Segundo Faria (2005, p. 15), na cidade de Leopoldina, MG, o percentual de lixo reciclável encontrado em sua pesquisa foi de $88,58 \%$. Nesta pesquisa, para fator de segurança, foi adotado o de $80 \%$, e os dados podem ser observados na Tabela 4.

Tabela 4 - Projeção da quantidade de resíduos recicláveis (toneladas/ano) a partir da população urbana no município de Araçatuba, SP, nos anos de operação do Aterro Sanitário

\begin{tabular}{ll|ll|ll|ll}
\hline \multicolumn{8}{c}{ Quantidade de resíduos recicláveis (toneladas/ano) } \\
\hline $\mathbf{2 0 1 6}$ & $40.986,49$ & $\mathbf{2 0 2 1}$ & $42.874,38$ & $\mathbf{2 0 2 6}$ & $45.068,89$ & $\mathbf{2 0 3 1}$ & $47.646,94$ \\
\hline $\mathbf{2 0 1 7}$ & $41.342,59$ & $\mathbf{2 0 2 2}$ & $43.286,66$ & $\mathbf{2 0 2 7}$ & $45.550,96$ & $\mathbf{2 0 3 2}$ & $48.217,17$ \\
\hline $\mathbf{2 0 1 8}$ & $41.708,84$ & $\mathbf{2 0 2 3}$ & $43.711,69$ & $\mathbf{2 0 2 8}$ & $46.049,02$ & $\mathbf{2 0 3 3}$ & $48.807,72$ \\
\hline $\mathbf{2 0 1 9}$ & $42.086,12$ & $\mathbf{2 0 2 4}$ & $44.149,90$ & $\mathbf{2 0 2 9}$ & $46.563,73$ & $\mathbf{2 0 3 4}$ & $49.419,87$ \\
\hline $\mathbf{2 0 2 0}$ & $42.474,41$ & $\mathbf{2 0 2 5}$ & $44.602,15$ & $\mathbf{2 0 3 0}$ & $47.096,15$ & $\mathbf{2 0 3 5}$ & $50.054,72$ \\
\hline
\end{tabular}

A Tabela 5 expressa a quantidade de resíduos que necessita ser enterrada, já que o reciclado seria $80 \%$ do material, o restante será enterrado. 
Tabela 5 - Projeção quantidade de resíduos recicláveis enterrados (toneladas/ ano) a partir da população urbana no município de Araçatuba, SP, nos anos de operação do Aterro Sanitário

\begin{tabular}{ll|ll|ll|ll}
\hline \multicolumn{7}{c}{ Quantidade de resíduos enterrados (toneladas/ano) } \\
\hline $\mathbf{2 0 1 6}$ & $10.246,62$ & $\mathbf{2 0 2 1}$ & $10.718,59$ & $\mathbf{2 0 2 6}$ & $11.267,22$ & $\mathbf{2 0 3 1}$ & $11.911,73$ \\
\hline $\mathbf{2 0 1 7}$ & $10.335,65$ & $\mathbf{2 0 2 2}$ & $10.821,66$ & $\mathbf{2 0 2 7}$ & $11.387,74$ & $\mathbf{2 0 3 2}$ & $12.054,29$ \\
\hline $\mathbf{2 0 1 8}$ & $10.427,21$ & $\mathbf{2 0 2 3}$ & $10.927,92$ & $\mathbf{2 0 2 8}$ & $11.512,26$ & $\mathbf{2 0 3 3}$ & $12.201,93$ \\
\hline $\mathbf{2 0 1 9}$ & $10.521,53$ & $\mathbf{2 0 2 4}$ & $11.037,47$ & $\mathbf{2 0 2 9}$ & $11.640,93$ & $\mathbf{2 0 3 4}$ & $12.354,97$ \\
\hline $\mathbf{2 0 2 0}$ & $10.618,60$ & $\mathbf{2 0 2 5}$ & $11.150,54$ & $\mathbf{2 0 3 0}$ & $11.774,04$ & $\mathbf{2 0 3 5}$ & $12.513,68$ \\
\hline
\end{tabular}

A quantidade de resíduos orgânicos está expressa na tabela 6 e, conforme Faria (2005, p. 14), o valor de matéria orgânica encontrado foi de 48,14\%; no presente estudo foi adotado o de $48 \%$.

Tabela 6 - Projeção quantidade de resíduos recicláveis que necessita ser enterrada (Toneladas/ano) a partir da população urbana no município de Araçatuba, SP, nos anos de operação do Aterro Sanitário

\begin{tabular}{ll|ll|ll|ll}
\hline \multicolumn{7}{c}{ Quantidade de resíduos orgânicos (toneladas/ano) } \\
\hline $\mathbf{2 0 1 6}$ & $24.591,89$ & $\mathbf{2 0 2 1}$ & $25.724,63$ & $\mathbf{2 0 2 6}$ & $27.041,33$ & $\mathbf{2 0 3 1}$ & $28.588,16$ \\
\hline $\mathbf{2 0 1 7}$ & $24.805,55$ & $\mathbf{2 0 2 2}$ & $25.971,99$ & $\mathbf{2 0 2 7}$ & $27.330,58$ & $\mathbf{2 0 3 2}$ & $28.930,30$ \\
\hline $\mathbf{2 0 1 8}$ & $25.025,31$ & $\mathbf{2 0 2 3}$ & $26.227,01$ & $\mathbf{2 0 2 8}$ & $27.629,41$ & $\mathbf{2 0 3 3}$ & $29.284,63$ \\
\hline $\mathbf{2 0 1 9}$ & $25.251,67$ & $\mathbf{2 0 2 4}$ & $26.489,94$ & $\mathbf{2 0 2 9}$ & $27.938,24$ & $\mathbf{2 0 3 4}$ & $29.651,92$ \\
\hline $\mathbf{2 0 2 0}$ & $25.484,65$ & $\mathbf{2 0 2 5}$ & $26.761,29$ & $\mathbf{2 0 3 0}$ & $28.257,69$ & $\mathbf{2 0 3 5}$ & $30.032,83$ \\
\hline
\end{tabular}

Segundo Sistemas Integrados de Destinação Final de Resíduos Sólidos Urbanos (LIMA, 2005), o valor de compactação é de 0,70 T/m³. Assim o volume de resíduo compactado disposto no aterro sanitário está expresso na Tabela 7. 
Tabela 7 - Projeção do volume de resíduo compactado disposto no aterro sanitário ( $\mathrm{m}^{3}$ /ano), a partir da população urbana no município de Araçatuba, SP, nos anos de operação do Aterro Sanitário

\begin{tabular}{ll|ll|ll|ll}
\hline \multicolumn{6}{c}{ Volume de resíduo compactado disposto no aterro sanitário (m/ano) } \\
\hline $\mathbf{2 0 1 6}$ & $14.638,03$ & $\mathbf{2 0 2 1}$ & $15.312,28$ & $\mathbf{2 0 2 6}$ & $16.096,03$ & $\mathbf{2 0 3 1}$ & $17.016,76$ \\
\hline $\mathbf{2 0 1 7}$ & $14.765,21$ & $\mathbf{2 0 2 2}$ & $15.459,52$ & $\mathbf{2 0 2 7}$ & $16.268,20$ & $\mathbf{2 0 3 2}$ & $17.220,42$ \\
\hline $\mathbf{2 0 1 8}$ & $14.896,02$ & $\mathbf{2 0 2 3}$ & $15.611,32$ & $\mathbf{2 0 2 8}$ & $16.446,08$ & $\mathbf{2 0 3 3}$ & $17.431,33$ \\
\hline $\mathbf{2 0 1 9}$ & $15.030,76$ & $\mathbf{2 0 2 4}$ & $15.767,82$ & $\mathbf{2 0 2 9}$ & $16.629,90$ & $\mathbf{2 0 3 4}$ & $17.649,95$ \\
\hline $\mathbf{2 0 2 0}$ & $15.169,43$ & $\mathbf{2 0 2 5}$ & $15.929,34$ & $\mathbf{2 0 3 0}$ & $16.820,05$ & $\mathbf{2 0 3 5}$ & $17.876,68$ \\
\hline
\end{tabular}

O volume de resíduo compactado disposto no aterro sanitário está expresso na Tabela 8.

Tabela 8 - Projeção do volume de resíduos compactados e dispostos no aterro por dia ( $\left.\mathrm{m}^{3} / \mathrm{dia}\right)$, a partir da população urbana no município de Araçatuba, SP, nos anos de operação do Aterro Sanitário

\begin{tabular}{ll|ll|ll|ll}
\multicolumn{6}{c}{ Volume de resíduo compactado disposto no aterro sanitário por dia (mªno) } \\
\hline $\mathbf{2 0 1 6}$ & 40,10 & $\mathbf{2 0 2 1}$ & 41,95 & $\mathbf{2 0 2 6}$ & 44,10 & $\mathbf{2 0 3 1}$ & 46,62 \\
\hline $\mathbf{2 0 1 7}$ & 40,45 & $\mathbf{2 0 2 2}$ & 42,35 & $\mathbf{2 0 2 7}$ & 44,57 & $\mathbf{2 0 3 2}$ & 47,18 \\
\hline $\mathbf{2 0 1 8}$ & 40,81 & $\mathbf{2 0 2 3}$ & 42,77 & $\mathbf{2 0 2 8}$ & 45,06 & $\mathbf{2 0 3 3}$ & 47,76 \\
\hline $\mathbf{2 0 1 9}$ & 41,18 & $\mathbf{2 0 2 4}$ & 43,20 & $\mathbf{2 0 2 9}$ & 45,56 & $\mathbf{2 0 3 4}$ & 48,36 \\
\hline $\mathbf{2 0 2 0}$ & 41,56 & $\mathbf{2 0 2 5}$ & 43,64 & $\mathbf{2 0 3 0}$ & 46,08 & $\mathbf{2 0 3 5}$ & 48,98 \\
\hline
\end{tabular}

A Tabela 9 evidencia o volume de solo de recobrimento ( $\mathrm{m}^{3} / \mathrm{ano}$ ). Foi adotado um recobrimento similar ao do projeto executivo do aterro de Bela Vista, GO, que foi de $20 \%$

Tabela 9 - Projeção do volume de solo de recobrimento ( $\mathrm{m}^{3} / \mathrm{ano}$ ), a partir da população urbana no município de Araçatuba, SP, nos anos de operação do Aterro Sanitário

\begin{tabular}{ll|ll|ll|ll}
\hline \multicolumn{7}{c}{ Volume de solo de recobrimento ( $\left.\mathbf{m}^{3} / \mathbf{a n o}\right)$} \\
\hline $\mathbf{2 0 1 6}$ & $2.929,62$ & $\mathbf{2 0 2 1}$ & $3.062,46$ & $\mathbf{2 0 2 6}$ & $3.219,21$ & $\mathbf{2 0 3 1}$ & $3.403,35$ \\
\hline $\mathbf{2 0 1 7}$ & $2.953,04$ & $\mathbf{2 0 2 2}$ & $3.091,90$ & $\mathbf{2 0 2 7}$ & $3.253,64$ & $\mathbf{2 0 3 2}$ & $3.444,08$ \\
\hline $\mathbf{2 0 1 8}$ & $2.979,20$ & $\mathbf{2 0 2 3}$ & $3.122,26$ & $\mathbf{2 0 2 8}$ & $3.289,22$ & $\mathbf{2 0 3 3}$ & $3.486,27$ \\
\hline $\mathbf{2 0 1 9}$ & $3.006,15$ & $\mathbf{2 0 2 4}$ & $3.153,56$ & $\mathbf{2 0 2 9}$ & $3.325,98$ & $\mathbf{2 0 3 4}$ & $3.529,99$ \\
\hline $\mathbf{2 0 2 0}$ & $3.033,89$ & $\mathbf{2 0 2 5}$ & $3.185,87$ & $\mathbf{2 0 3 0}$ & $3.364,01$ & $\mathbf{2 0 3 5}$ & $3.575,34$ \\
\hline
\end{tabular}


O volume total do aterro sanitário está expresso na Tabela 10.

Tabela 10 - Projeção do volume total do aterro sanitário ( $\mathrm{m}^{3} / \mathrm{ano}$ ), a partir da população urbana no município de Araçatuba, SP, nos anos de operação do Aterro Sanitário

\begin{tabular}{ll|ll|ll|ll}
\hline \multicolumn{7}{c}{ Volume total do aterro sanitário (m/3ano) } \\
\hline $\mathbf{2 0 1 6}$ & $17.565,64$ & $\mathbf{2 0 2 1}$ & $18.374,73$ & $\mathbf{2 0 2 6}$ & $19.315,24$ & $\mathbf{2 0 3 1}$ & $20.420,12$ \\
\hline $\mathbf{2 0 1 7}$ & $17.718,25$ & $\mathbf{2 0 2 2}$ & $18.551,42$ & $\mathbf{2 0 2 7}$ & $19.521,84$ & $\mathbf{2 0 3 2}$ & $20.664,50$ \\
\hline $\mathbf{2 0 1 8}$ & $17.875,22$ & $\mathbf{2 0 2 3}$ & $18.733,58$ & $\mathbf{2 0 2 8}$ & $19.735,30$ & $\mathbf{2 0 3 3}$ & $20.917,59$ \\
\hline $\mathbf{2 0 1 9}$ & $18.036,91$ & $\mathbf{2 0 2 4}$ & $18.921,38$ & $\mathbf{2 0 2 9}$ & $19.955,88$ & $\mathbf{2 0 3 4}$ & $21.179,95$ \\
\hline $\mathbf{2 0 2 0}$ & $18.203,32$ & $\mathbf{2 0 2 5}$ & $19.115,21$ & $\mathbf{2 0 3 0}$ & $20.184,06$ & $\mathbf{2 0 3 5}$ & $21.452,02$ \\
\hline
\end{tabular}

O volume de operação acumulado no aterro sanitário é calculado para cada ano até o final do horizonte de projeto, sendo o volume inicial dado pelo volume do ano base. Em seguida, a determinação dos próximos anos foi realizada através do somatório entre o ano base e o seguinte (Tabela 11).

Tabela 11 - Projeção do volume acumulado no aterro sanitário ( $\mathrm{m}^{3} / \mathrm{ano}$ ), a partir da população urbana no município de Araçatuba, SP, nos anos de operação do Aterro Sanitário

\begin{tabular}{ll|ll|ll|ll}
\hline \multicolumn{8}{c}{ Volume acumulado no aterro sanitário ( $\mathbf{3} /$ ano) } \\
\hline $\mathbf{2 0 1 6}$ & $17.565,64$ & $\mathbf{2 0 2 1}$ & $107.774,07$ & $\mathbf{2 0 2 6}$ & $202.410,90$ & $\mathbf{2 0 3 1}$ & $302.228,10$ \\
\hline $\mathbf{2 0 1 7}$ & $35.283,89$ & $\mathbf{2 0 2 2}$ & $126.325,49$ & $\mathbf{2 0 2 7}$ & $221.932,74$ & $\mathbf{2 0 3 2}$ & $322.892,60$ \\
\hline $\mathbf{2 0 1 8}$ & $53.159,11$ & $\mathbf{2 0 2 3}$ & $145.059,07$ & $\mathbf{2 0 2 8}$ & $241.668,04$ & $\mathbf{2 0 3 3}$ & $343.810,20$ \\
\hline $\mathbf{2 0 1 9}$ & $71.196,01$ & $\mathbf{2 0 2 4}$ & $163.980,46$ & $\mathbf{2 0 2 9}$ & $261.623,92$ & $\mathbf{2 0 3 4}$ & $364.990,14$ \\
\hline $\mathbf{2 0 2 0}$ & $89.399,33$ & $\mathbf{2 0 2 5}$ & $183.095,67$ & $\mathbf{2 0 3 0}$ & $281.807,99$ & $\mathbf{2 0 3 5}$ & $386.442,16$ \\
\hline
\end{tabular}

O Volume médio de operação durante os 20 anos é de 19.332,11 m³. Será realizada a impermeabilização com manta Polietileno de Alta Densidade (PEAD), adotando uma dimensão de 146 por 216 metros, uma profundidade de escavação de 15 metros conforme aterro já instalado ao lado (CULOSSI, 2002), a inclinação dos taludes de 1:1, finalizando com dimensão de base de 116 por 186 metros, será necessário utilizar 5 metros sobre a superfície, totalizando um volume de $426880 \mathrm{~m}^{3}$. 
Foi dimensionada a vazão drenada pelo método racional, a intensidade da chuva crítica adotada foi $0,0001389 \mathrm{~m} / \mathrm{s}$, conforme fornecido e conferido pelo site CIIAGRO e Programa Past, e foi a maior precipitação do período analisado, de 01/05/2006 a 01/05/2016, sendo o coeficiente de escoamento superficial, adotado 0,22 conforme solo e a declividade (SUMI, 2009), adquirindo assim uma vazão de $0,96 \mathrm{~m}^{3} / \mathrm{s}$.

Foi utilizado o método equacional de Chézy-Manning (AZEVEDO, 1998), resultando em um diâmetro de 81 centímetros para o dimensionamento do canal das águas pluviais.

A vazão de percolado a ser drenada foi calculada a partir do método suíço (SILVA; FERREIRA, 2005). Onde a precipitação é de 155,61 mm conforme a CIIAGRO (s.d.), e o coeficiente que depende do grau de compactação é de 0,5 , obtém-se assim uma vazão de 0,000077 m³.s.

O dimensionamento do dreno foi realizado a partir da lei de Darcy (BRASIL, 2006), em que se encontrou que seria necessário um dreno de área de $0,00856 \mathrm{~m}^{2}$; como a execução será feita de forma quadrada e a largura da base será $60 \mathrm{~cm}$, será realizado um dreno de 60×60 cm.

No presente estudo, sugere-se a comercialização do percolado em forma de adubo, principalmente para plantas ornamentais utilizadas em paisagismo. Sugere-se ainda o método de minhocultura, para a compostagem do material orgânico separado no processo de triagem, gerando como resultado húmus e um percolado que não possui mau cheiro (COSTA; CARDOSO, 2011). O húmus será comercializado, gerando assim renda para o aterro; conforme a empresa Anhumus, o valor de húmus varia de $\mathrm{R} \$ 2,50$, o saco com $2 \mathrm{~kg}$, a $R \$ 275,00$ a tonelada do produto, segundo preço praticado no mercado.

Conforme Pinto e Hata (s.d.), o prazo de produção de húmus se dá entre 15 dias e 20 dias no inverno, já em períodos de frio pode chegar a seus 45 dias. Para evitar problemas, o tempo previsto em projetos será de 60 dias, sendo um minhocário responsável por cada mês, sendo dimensionado para atender o volume do último ano do estudo com $40 \%$ de folga. Como esse material não será compactado pode-se adotar que a quantidade de material orgânico será igual ao volume, e o volume mensal com folga é de $3503,84 \mathrm{~m}^{3}$. Adotando uma altura de 10 metros e a base quadrada de 20 metros, tendo assim um volume de $4000 \mathrm{~m}^{3}$. 
Segundo Schiedeck, Gonçalves e Schwengber (2006), cada minhoca consome basicamente seu peso em alimento por dia, sendo aproximadamente 1 grama; segundo Penteaado (s.d.), a cada 2 meses dobra-se a população de minhocas presentes no ambiente, sendo assim, a quantidade necessária de minhocas para o primeiro mês de trabalho do aterro é de 2.049.324.166, seu controle subsequente através da comercialização do excedente.

Aproximadamente $50 \%$ de todo material compostado vira húmus (OLIVEIRA; SARTORI; GARCEZ, 2008, p. 15). Na Tabela 12, está expressa a quantidade de humus produzido.

Tabela 12 - Projeção da quantidade de Húmus produzido (tonelada/ano), a partir da população urbana no município de Araçatuba, SP, nos anos de operação do Aterro Sanitário

\begin{tabular}{ll|lll|ll|ll}
\hline \multicolumn{7}{c}{ Quantidade de húmus produzido (tonelada/ano) } \\
\hline $\mathbf{2 0 1 6}$ & $12.295,95$ & $\mathbf{2 0 2 1}$ & $12.862,31$ & $\mathbf{2 0 2 6}$ & $13.520,67$ & $\mathbf{2 0 3 1}$ & $14.294,08$ \\
\hline $\mathbf{2 0 1 7}$ & $12.402,78$ & $\mathbf{2 0 2 2}$ & $12.986,00$ & $\mathbf{2 0 2 7}$ & $13.665,29$ & $\mathbf{2 0 3 2}$ & $14.465,15$ \\
\hline $\mathbf{2 0 1 8}$ & $12.512,65$ & $\mathbf{2 0 2 3}$ & $13.113,51$ & $\mathbf{2 0 2 8}$ & $13.814,71$ & $\mathbf{2 0 3 3}$ & $14.642,32$ \\
\hline $\mathbf{2 0 1 9}$ & $12.625,84$ & $\mathbf{2 0 2 4}$ & $13.244,97$ & $\mathbf{2 0 2 9}$ & $13.969,12$ & $\mathbf{2 0 3 4}$ & $14.825,96$ \\
\hline $\mathbf{2 0 2 0}$ & $12.742,32$ & $\mathbf{2 0 2 5}$ & $13.380,65$ & $\mathbf{2 0 3 0}$ & $14.128,84$ & $\mathbf{2 0 3 5}$ & $15.016,41$ \\
\hline
\end{tabular}

Adotando-se sacos de $2 \mathrm{~kg}$ para comercialização, tal qual a empresa Anhumus, escolhida como comércio local, com o mesmo valor onde se adquire uma renda estimada com o que se apresenta na Tabela 13.

Tabela 13 - Projeção do valor em reais $(R \$)$ da renda de comercialização de Húmus produzido, a partir da população urbana no município de Araçatuba, SP, nos anos de operação do Aterro Sanitário.

\begin{tabular}{ll|ll|lll|ll}
\hline \multicolumn{8}{c}{ Valor da renda gerada através da comercialização dos húmus } \\
\hline $\mathbf{2 0 1 6}$ & $15.369 .932,46$ & $\mathbf{2 0 2 1}$ & $16.077 .891,57$ & $\mathbf{2 0 2 6}$ & $16.900 .832,25$ & $\mathbf{2 0 3 1}$ & $17.867 .601,18$ \\
\hline $\mathbf{2 0 1 7}$ & $15.503 .469,90$ & $\mathbf{2 0 2 2}$ & $16.232 .496,81$ & $\mathbf{2 0 2 7}$ & $17.081 .610,18$ & $\mathbf{2 0 3 2}$ & $18.081 .439,35$ \\
\hline $\mathbf{2 0 1 8}$ & $15.640 .815,75$ & $\mathbf{2 0 2 3}$ & $16.391 .882,82$ & $\mathbf{2 0 2 8}$ & $17.081 .610,18$ & $\mathbf{2 0 3 3}$ & $18.302 .894,34$ \\
\hline $\mathbf{2 0 1 9}$ & $15.782 .294,13$ & $\mathbf{2 0 2 4}$ & $16.556 .211,66$ & $\mathbf{2 0 2 9}$ & $17.461 .397,79$ & $\mathbf{2 0 3 4}$ & $18.532 .452,33$ \\
\hline $\mathbf{2 0 2 0}$ & $15.929 .905,04$ & $\mathbf{2 0 2 5}$ & $16.725 .807,45$ & $\mathbf{2 0 3 0}$ & $17.661 .055,71$ & $\mathbf{2 0 3 5}$ & $18.770 .518,47$ \\
\hline
\end{tabular}


A figura 1 evidencia a planta baixa de aterro sanitário, projetada para o município de Araçatuba, SP.

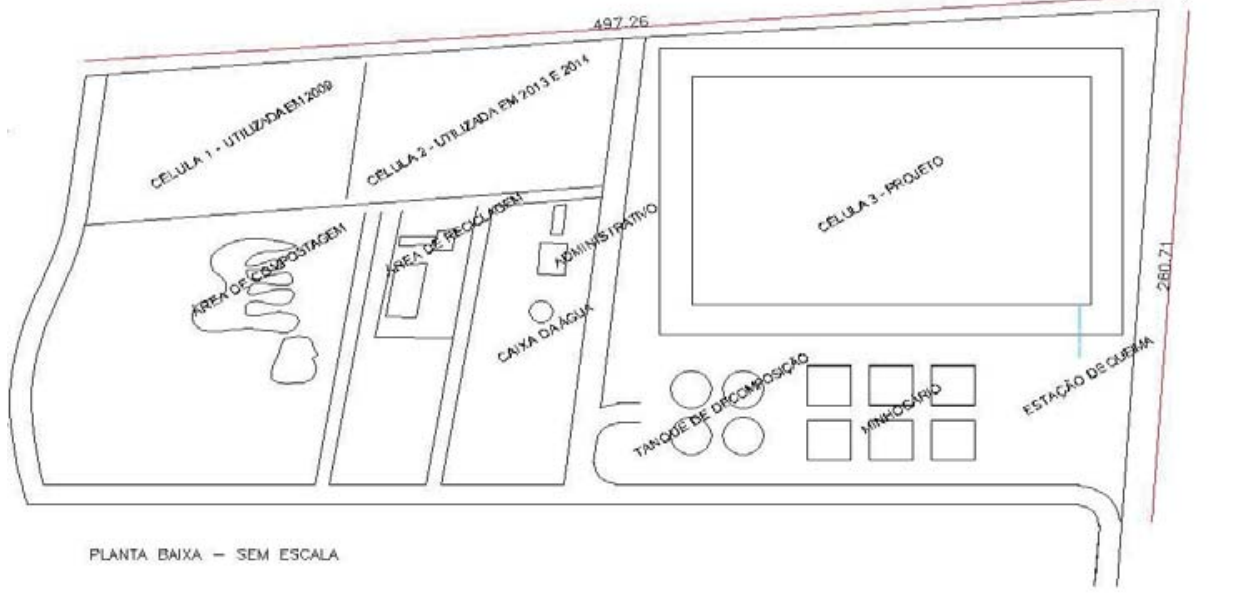

Figura 1 - Planta baixa de aterro sanitário projetada para o município de Araçatuba, SP

\section{CONCLUSÕES}

De acordo com razões técnicas e econômicas, a ampliação do atual aterro sanitário é viável, já que a prefeitura havia desapropriado uma área destinada à ampliação. O tratamento dos resíduos sólidos em Araçatuba, SP, possui qualidade similar a do que é realizado no município de Paulínia, SP, e ambos possuem distância aproximada entre o aterro sanitário e o aeroporto, que é de 6,50 quilômetros; porém a área no município é menor, e a quantidade de resíduos recebidos por dia também, aliada ao menor tráfego aéreo do que Paulínia, que está localizado dentro da Região Metropolitana de Campinas. O presente estudo ainda ressalta a necessidade de ampliar e reforçar os programas de educação socioambiental, realização de oficinas pedagógicas, coleta seletiva, programas de reciclagem, incentivando as cooperativas de materiais reciclados. Havendo isso de forma bem planejada e executada, teremos como resultado a redução da quantidade de resíduos sólidos para serem aterrados. 


\section{REFERÊNCIAS}

ARAÇATUBA (Cidade). Lei n. 7.525, de 12 de abril de 2013. Dispõe sobre a proibição de recebimento de resíduos e de rejeitos de qualquer natureza, proveniente de outros municípios, no aterro sanitário de Araçatuba ou em qualquer outro equipamento ou empreendimento público, privado ou público-privado no Município de Araçatuba. Disponível em: <http://www.camaraaracatuba.com.br/ site/legislacao/legislacao.asp>. Acesso em: 11 maio 2016.

. Projeto de melhoria da estrutura de equipamentos públicos e programas de saúde do município de Araçatuba - SP. [s.d.]. Disponível em: <http://www. camaraaracatuba.com.br/site/legislacao/legislacao.asp>. Acesso em: 11 maio 2016.

. Lei n. 6.904, de 4 de setembro de 2007. Dispõe sobre a proibição do recebimento de lixo de qualquer natureza, seja domiciliar, industrial, hospitalar, agrícola ou tecnológico, proveniente de outros municípios, no aterro sanitário de Araçatuba. Disponível em: <http://www.camaraaracatuba.com.br/site/legislacao/ legislacao.asp>. Acesso em: 11 maio 2016.

ASSOCIAÇÃO BRASILEIRA DE NORMAS TÉCNICAS (ABNT). NBR 10004: Resíduos sólidos- classificação. Rio de Janeiro, 2004, 71p.

. NBR 13896: Aterros de resíduos não perigosos - critérios para projeto, implantação e operação. Rio de Janeiro, 1997. 12p.

AZEVedo NetO, J. M. et al. Manual de Hidráulica. 8. Ed. São Paulo: E. Edgard Blücher, 1998.

BRASIL. Ministério da Defesa. Comando da Aeronáutica. Centro de Investigação e Prevenção de Acidentes Aeronáuticos. PCA 3-3 Plano Básico de Gerenciamento de Risco de Fauna. Brasília, DF, 2017. [Apostila]. Disponível em: <http://www2.fab.mil. br/cenipa/index.php/prevencao/risco-de-fauna/pbgrf>. Acesso em: 22 mar. 2018.

. Presidência da República Casa Civil. Lei n. 12.725, de 16 de outubro de 2012. Dispõe sobre o controle da fauna nas imediações de aeródromos. Brasília, DF, 2012. Disponível em:<http://www.planalto.gov.br/ccivil_03/_Ato2011-2014/2012/ Lei/L12725.htm>. Acesso em: 11 maio 2016.

. Comando da Aeronáutica. Investigação e Prevenção de Acidentes Aeronáuticos. Plano básico de gerenciamento do risco aviário. 2011. [Apostila]. Disponível em: <http://www.cenipa.aer.mil.br/cenipa/Anexos/article/205/PCA_32_PBGRA.pdf>. Acesso em: 22 maio 2016.

. Departamento Nacional de Infra-Estrutura de Transportes. Manual de drenagem de rodovias. 2. ed. Rio de Janeiro: DNIT, 2006. Disponível em: <http:// www1.dnit.gov.br/normas/download/Manual_de_Drenagem_de_Rodovias.pdf>. Acesso em: 19 maio 2016. 
CENTRO INTEGRADO DE INFORMAÇÕES AGROMETEOROLÓGICAS (CIIAGRO). [s.d.]. Disponível em: <http://www.ciiagro.sp.gov.br/>. Acesso em: 11 maio 2016.

COMITÊ DA BACIA HIDROGRÁFICA DO BAIXO TIETÊ (CBH-BT). Deliberação CBH-BT n. 124/2013. Birigui, SP, maio 2013. Disponível em: <http://www.sigrh.sp.gov.br/ public/uploads/deliberation/\%5C5949/deliberacao-124-2013-cgr-aracatuba.pdf>.

COMPANHIA AMBIENTAL DO ESTADO DE SÃO PAULO (CETESB). Inventário Estadual de Resíduos Sólidos Urbanos de 2014. São Paulo: CETESB, 2015. (Série Relatórios). Disponível em: <http://residuossolidos.cetesb.sp.gov.br/wp-content/uploads/ sites/36/2013/11/residuosSolidos2014.pdf>. Acesso em: 11 maio 2016.

CONSELHO NACIONAL DO MEIO AMBIENTE (CONAMA). Resolução CONAMA n. 4, de 9 de outubro de 1995. Disponível em: <www.cprh.pe.gov.br/downloads/ 4de9deoutubrode1995.doc>. Acesso em: 22 maio 2016.

COSTA, Ruy Fabio Melo; CARDOSO, Raisa Nicole Campos. Reaproveitamento do lixo orgânico como forma de produção de biofertilizante na região Norte. In: ENCONTRO NACIONAL DE ENGENHARIA DE PRODUÇÃO, 31., Belo Horizonte, MG, 4-7 out. 2011. Anais... Belo Horizonte: Enegep, 2011.

CULOSSI, Juliana. Aterro sanitário começa a funcionar na segunda-feira. Folha da Região, Araçatuba, 18 maio 2002. Disponível em: <http://www.folhadaregiao.com. br/jornal/2002/05/18/cida02.php>. Acesso em: 19 maio 2016.

EMPRESA BRASILEIRA DE PESQUISA AGROPECUÁRIA (EMBRAPA). Minhocultura e produção de húmus para a agricultura familiar. Pelotas: EMBRAPA, dez. 2006. (Circular Técnica, 57). Disponível em: <http://www.infoteca.cnptia.embrapa.br/ bitstream/doc/746014/1/Circular57.pdf>. Acesso em: 28 maio 2016.

FARIA, Mário Rubens Antunes. Caracterização do resíduo sólido urbano da cidade de Leopoldina-MG: proposta de implantação de um centro de triagem. Revista APS, Juiz de Fora, v. 8, n. 2, p. 96-108, jul./dez. 2005. Disponível em: <http://www.ufjf. br/nates/files/2009/12/caractsolo.pdf>. Acesso em: 19 maio 2016.

FURTADO, Zeide Nogueira de Camargo. Serviços Técnicos de Consultoria sobre Normas Técnicas- aterro sanitário. CGR Araçatuba - Associação dos Engenheiros e Arquitetos da Alta Noroeste (AEAN). CREA SP - ART 92221220130564039. Araçatuba, 6 mar. 2013.

. Vistoria e parecer técnico ambiental. CGR Araçatuba, Ministério Público Estadual, São Paulo. CREA SP- ART 92221220150785992. Araçatuba, 25 fev. 2015.

G1. Araçatuba completa 106 anos de história; conheça curiosidades. Globo.com, Rio Preto e Araçatuba, 2 dez. 2014. Disponível em: <http://g1.globo.com/sao-paulo/ sao-jose-do-rio-preto-aracatuba/noticia/2014/12/aracatuba-completa-106-anosde-historia-conheca-curiosidades.html>. Acesso em: 13 mar. 2016. 
GALDINO, Ronaldo Ruiz. Edna promete brigar por expansão do atual aterro. Folha da Região, Araçatuba, 19 fev. 2016. Disponível em: <http://www.folhadaregiao. com.br/Materia.php?id=394823>. Acesso em: 18 jun. 2016.

INSTITUTO BRASILEIRO DE GEOGRAFIA E ESTATISTICA (IBGE). Araçatuba infográficos: dados gerais do município. 2009. Disponível em: <http://cidades.ibge. gov.br/painel/painel.php?codmun=350280>. Acesso em: 12 mar. 2016.

. Araçatuba- infográficos: dados gerais do município. 2002. Disponível em: <http://cidades.ibge.gov.br/painel/painel.php?codmun=350280>. Acesso em: 12 mar. 2016.

LIMA, José Dantas. Sistema Integrados de Destinação Final de Resíduos Sólidos Urbanos. 1. ed. Paraíba: ABES, 2005.

MANSOR, Maria Teresa Castilho; CAMARÃO, Teresa Cristina Ramos Costa; CAPELINI, Márcia; KOVACS, André; FILET, Martinus; SANTOS, Gabriela de Araújo; SILVA, Amanda Brito. Resíduos sólidos. São Paulo: Secretaria do Meio Ambiente, 2010. 152 p. (Cadernos de Educação Ambiental). Disponível em: <http://www.ambiente. sp.gov.br/cea/2014/11/19/6-residuos-solidos/>. Acesso em: 18 maio 2016.

OLIVEIRA, Emídio Cantídio Almeida; SARTORI, Raul Henrique; GARCEZ, Tiago B. Compostagem. Curso de Pós-Graduação em Solos e Nutrientes de Plantas, Universidade de São Paulo (USP), Piracicaba, SP, 2008. 19f. Disponível em: <http:// www.agencia.cnptia.embrapa.br/Repositorio/Compostagem_000fhc8nfqz02wyiv 80efhb2adn37yaw.pdf>. Acesso em: 11 maio 2016.

PAULÍNIA, Cidade [de]. Lei Complementar n. 53, de 26 de dezembro de 2011. Dispõe sobre o parcelamento, uso e ocupação do solo no município de Paulínia, e dá outras providências. Disponível em: <http://consulta.siscam.com.br/camarapaulinia/ arquivo id=39415> . Acesso em: 11 maio 2016.

- Lei n. 2.852, de 22 de dezembro de 2006. Institui o plano diretor do município de Paulínia. Disponível em: <http://consulta.siscam.com.br/ camarapaulinia/arquivo?id=36566>. Acesso em: 11 maio 2016.

PENTEAADO, Silvio Roberto. Produção de húmus de minhoca. Infobibos, Campinas, s.d. Disponível em: <http://cursos.infobibos.com/cursosonline/Aulas/Agrorganica/ Aula9/Anexo\%209\%20-\%20H\%C3\%BAmus\%20de\%20Minhoca.pdf >. Acesso em: 25 maio 2016.

PINTO, Gheysa Julio; HATA, Fernando Teruhiko. Implantação e manejo de minhocário de baixo custo. [s.d.]. Disponível em: <http://www.unitrabalho.uem.br/ administracao/bd_livros/arquivos/010814093440-2.pdf>. Acesso em: 22 maio 2016.

PLANO MUNICIPAL de Abastecimento de Água e Esgotamento Sanitário do Município de Araçatuba. Diagnóstico dos sistemas e serviços de abastecimento de 
água e esgotamento sanitário. Versão Final. 2011. Disponível em: <http://aracatuba. sp.gov.br/relatorio-final-plano-de-saneamento-daea-tomo-i-2/\#>. Acesso em: 12 mar. 2016.

SÃO PAULO, Estado [de]. Ministério Público do Estado de São Paulo. Ação Civil Pública Urbanístico-Ambiental com pedido de liminar, de 3 de março de 2016. Disponível em: <http://www.mpsp.mp.br/portal/pls/portal/!PORTAL.wwpob_page. show?_docname=2584027.PDF>. Acesso em: 20 maio 2016.

Sistema Integrado de Gerenciamento de Recursos Hídricos (SIGRH). Deliberação CBH-BT n. 124, de 3 de maio de 2013. Birigui, 2013. Disponível em: <http://www.sigrh.sp.gov.br/public/uploads/deliberation/\%5C5949/deliberacao124-2013-cgr-aracatuba.pdf>. Acesso em: 18 maio 2016.

SCHIEDECK, G.; GONÇALVES, M. de M.; SCHWENGBER, J. E. Minhocultura e produção de húmus para a agricultura familiar. Pelotas: Embrapa Clima Temperado, 2006. 11 p. (Circular técnica, 57).

SILVA, Lais Coelho. Cálculo do fator topográfico da equação universa de perda de solos na bacia do córrego baguaçu, Araçatuba-SP utilizando sig. In: CONGRESSO IBEROAMERICANO DE ESTUDIOS TERRITORIALES Y AMBIENTALES, 6., São Paulo, 8-12 set. 2014. Anais... São Paulo: USP, 2014. Disponível em: <http://6cieta.org/ arquivos-anais/eixo6/Lais\%20Coelho\%20Nascimento\%20Silva,\%20Ailton\%20 Luchiari.pdf>.cAcesso em: 24 mar. 2016.

SILVA, Lais Coelho. Cálculo do fator topográfico da equação universa de perda de solos na bacia do córrego baguaçu, Araçatuba-SP utilizando sig'. In: CONGRESSO IBEROAMERICANO DE ESTUDIOS TERRITORIALES Y AMBIENTALES, 6., São Paulo, 8-12 set. 2014. Anais... São Paulo: USP, 2014. Disponível em: <http://6cieta.org/ arquivos-anais/eixo6/Lais\%20Coelho\%20Nascimento\%20Silva,\%20Ailton\%20 Luchiari.pdf>.cAcesso em: 24 mar. 2016.

SILVA, Renato Pires; FERREIRA, Osmar Mendes. Aterro sanitário de Aparecida de Goiânia, medição da vazão de chorume. Goiânia. 2005. Disponível em: <http:// www.ucg.br/ucg/prope/cpgss/ArquivosUpload/36/file/Continua/ATERRO\%20 SANIT\%C3\%81RIO\%20DE\%20APARECIDA\%20DE\%20GOI\%C3\%82NIA, pdf>. Acesso em: 19 maio 2016.

SOLUÇÕES AMBIENTAIS DE ARAÇATUBA (SAMAR). Coleta e tratamento. 2016. Disponível em: <https://samar.eco.br/esgoto/coleta-e-tratamento>. Acesso em: 20 maio 2016.

SUMI, Ernesto Massayoshi. Estudo hidrogeológico de um aterro sanitário instalado em uma antiga área de disposição irregular de resíduos sólidos. São Paulo, 2009. 164 p. Dissertação (Mestrado em Recursos Minerais e Hidrogeologia)- Instituto de Geociências, Universidade de São Paulo (USP), São Paulo, SP, 2009. 
